\title{
TU/e emonown

\section{How antibody surface coverage on nanoparticles determines the activity and kinetics of antigen capturing for biosensing}

\section{Citation for published version (APA):}

Saha, B., Evers, T. H., \& Prins, M. W. J. (2014). How antibody surface coverage on nanoparticles determines the activity and kinetics of antigen capturing for biosensing. Analytical Chemistry, 86(16), 8158-66.

https://doi.org/10.1021/ac501536z

DOI:

10.1021/ac501536z

Document status and date:

Published: 01/01/2014

\section{Document Version:}

Publisher's PDF, also known as Version of Record (includes final page, issue and volume numbers)

\section{Please check the document version of this publication:}

- A submitted manuscript is the version of the article upon submission and before peer-review. There can be important differences between the submitted version and the official published version of record. People interested in the research are advised to contact the author for the final version of the publication, or visit the $\mathrm{DOI}$ to the publisher's website.

- The final author version and the galley proof are versions of the publication after peer review.

- The final published version features the final layout of the paper including the volume, issue and page numbers.

Link to publication

\section{General rights}

Copyright and moral rights for the publications made accessible in the public portal are retained by the authors and/or other copyright owners and it is a condition of accessing publications that users recognise and abide by the legal requirements associated with these rights.

- Users may download and print one copy of any publication from the public portal for the purpose of private study or research.

- You may not further distribute the material or use it for any profit-making activity or commercial gain

- You may freely distribute the URL identifying the publication in the public portal.

If the publication is distributed under the terms of Article 25fa of the Dutch Copyright Act, indicated by the "Taverne" license above, please follow below link for the End User Agreement:

www.tue.nl/taverne

Take down policy

If you believe that this document breaches copyright please contact us at:

openaccess@tue.nl

providing details and we will investigate your claim. 


\title{
How Antibody Surface Coverage on Nanoparticles Determines the Activity and Kinetics of Antigen Capturing for Biosensing
}

\author{
Bedabrata Saha, Toon H. Evers, and Menno W. J. Prins* ${ }^{*}$ \\ Philips Research, High Tech Campus, 5656 AE Eindhoven, The Netherlands \\ Supporting Information
}

ABSTRACT: The antigen-capturing activity of antibodycoated nanoparticles is very important for affinity-based bioanalytical tools. In this paper, a comprehensive study is reported of the antigen-capturing activity of antibodies that are nondirectionally immobilized on a nanoparticle surface. Superparamagnetic nanoparticles $(500 \mathrm{~nm})$ were covalently functionalized with different quantities of monoclonal antibodies against cardiac troponin I (cTnI). At a low antibody surface coverage, up to $4 \%$ of the immobilized antibodies could capture antigen molecules from solution. At high antibody coverage $\left(\geq 50 \times 10^{2}\right.$ antibodies per nanoparticle, i.e., $\geq 64 \times$ $10^{2}$ antibodies per $\mu \mathrm{m}^{2}$ ), the fraction of antigen-capturing antibodies drops well below $4 \%$ and the number of active antibodies saturates at about 120 per nanoparticle. The fraction of active antibodies is small, yet surprisingly their dissociation constants $\left(K_{\mathrm{d}}\right)$ are low, between 10 and 200 pM. In addition, the surface-binding activity of the antibody-coated nanoparticles was analyzed in an optomagnetic sandwich immunoassay biosensor, measuring cTnI in undiluted blood plasma. The data show that the immunoassay response scales with the number of active antibodies, increasing initially and saturating at higher antibody densities. The observations are summarized in a molecular sketch of the attachment, ordering, and functionality of antibodies on the nanoparticle surface.
$\mathrm{T}$ he binding of antigens by antibodies is at the basis of immunodiagnostics, and in many immunodiagnostic technologies, the antibodies are coupled to micro- or nanoparticles, because such particles provide a large surfaceto-volume ratio, facilitate detection and manipulation, provide good stability, and because a versatile toolbox of biochemical functionalizations is available. ${ }^{1,2}$ The bio-functionalized particles are used for specific capture of biomarkers and can also be used as labels in a subsequent detection step. ${ }^{3,4}$ In all cases, the antigen-capturing activity of the antibodies is crucial and this strongly depends on the immobilization strategy. The process to anchor the antibody molecules to the particle surface is a delicate balance between, on the one hand, the need to reliably attach the antibodies to the nanoparticle surface, and on the other hand, the need to keep the antibodies in a biologically active molecular conformation with a high accessibility for capturing antigens from solution. A stable link is needed between antibody and particle, while minimally changing the antibody molecule and without reducing its interaction with the solution.

Many different approaches have been developed to immobilize antibodies to particle surfaces, such as physical adsorption, covalent immobilization (directional and nondirectional), and bio-affinity based immobilization, e.g., biotinstreptavidin, protein $\mathrm{G}$ mediated. Covalent immobilization of antibodies gives the most stable link. Commonly used heterocross-linkers are, for example, 1-ethyl-3-(3-(dimethylamino)-

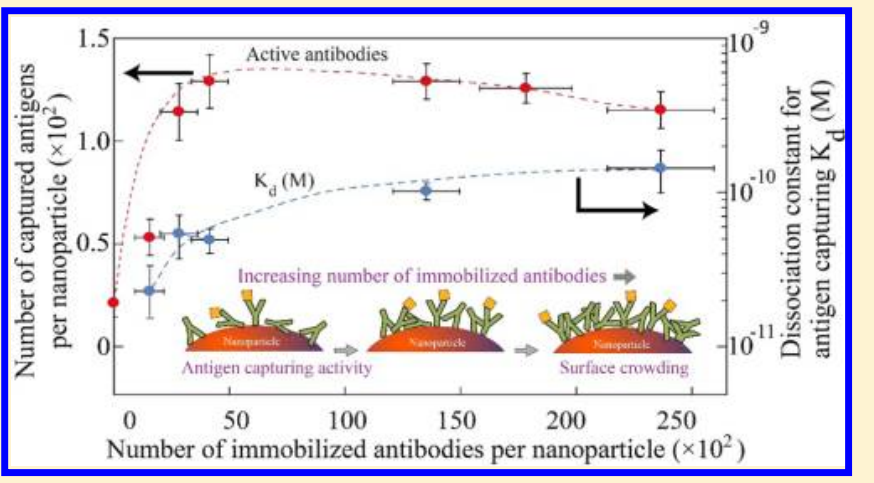

propyl)carbodiimide (EDC) and $N$-hydroxysuccinimide (NHS), which utilize the primary amine $\left(-\mathrm{NH}_{2}\right)$ groups of the amino acid side chains (Lys) of protein molecules for crosslinking $^{5}$ on a carboxyl $(-\mathrm{COOH})$ modified surface. Other cross-linking strategies using $-\mathrm{SH}$ (cysteine), ${ }^{6}-\mathrm{COOH}$ (Asp, $\mathrm{Glu}){ }^{7}$ and $-\mathrm{OH}$ (Ser, Thr) side groups of amino acids have also been investigated widely to conjugate on maleimide, amine, and epoxy ${ }^{8}$ modified surfaces, respectively. Directional covalent immobilization of antibodies has been reported via the carbohydrate moiety in the antibody Fc region; however, this requires prior modification and purification of antibody molecules. ${ }^{9}$ Covalent immobilization of antibodies using EDC and NHS is an easy, widely used immobilization strategy that is generally applicable for affinity based assays; however, due to the multiple binding sites, the antibody molecules are nondirectionally coupled. This generates a distribution of bonds (single to multiple bonding between the antibody and the particle surface) and a distribution of antibody orientations. Studies on solid substrates have reported that different factors can influence the antigen-capturing activity of the antibodies, such as the antibody orientation and antibody surface density. It has been established that Fab fragment availability toward the

Received: April 8, 2014

Accepted: July 21, 2014

Published: July 21, 2014 
Scheme 1. Schematic Illustration of the Work Performed in This Study ${ }^{a}$

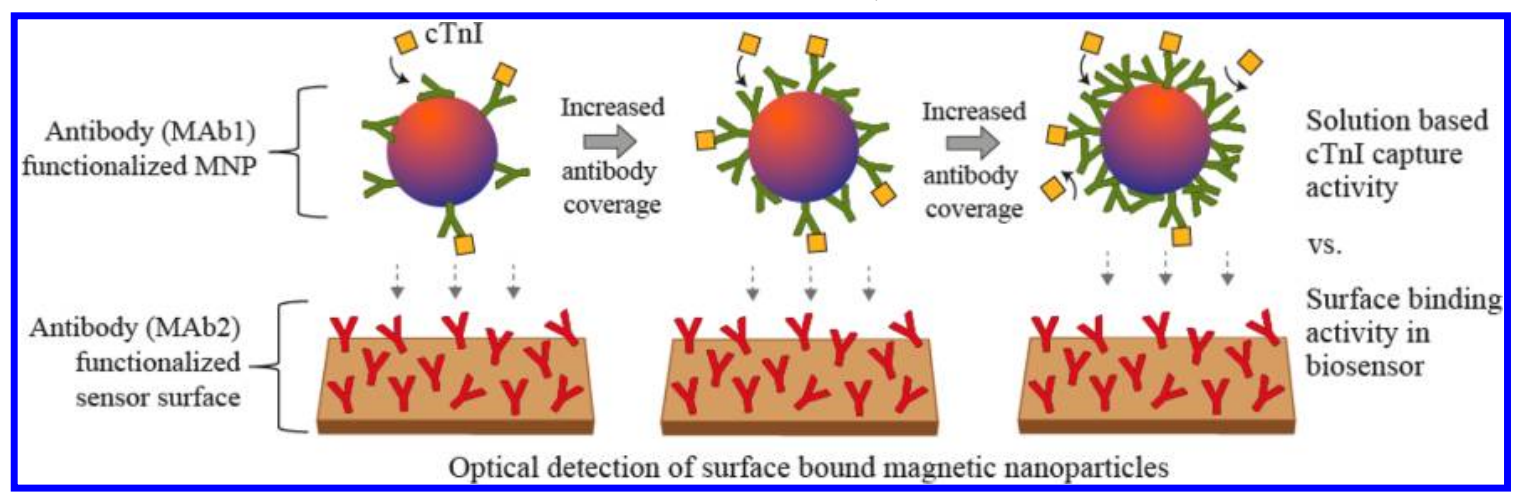

${ }^{a}$ Monoclonal anti-troponin antibodies (MAb1) were immobilized on $500 \mathrm{~nm}$ magnetic nanoparticles (MNP) at increasing surface coverages. The troponin I (cTnI) capturing kinetics and the number of active antibodies on nanoparticle surface have been quantified. Furthermore, the binding to a substrate coated with a secondary antibody (MAb2) has been studied in a sandwich immunoassay.

solution yields a higher affinity at the solid-liquid interface, and that the Fab availability is significantly affected by the density of immobilized antibodies. ${ }^{10-14}$ However, a comprehensive study analyzing the total number of antibodies, the number of active antibodies, and the kinetics of antigen capturing is not yet available.

In this paper, we focus on the nondirectional immobilization of antibodies on particles and we address two questions that are very important for nanoparticle-based biosensing. First, we study how the antigen-capturing activity and kinetics depend on the density at which the antibodies are immobilized on the nanoparticles. The antibody activity corresponds to the fraction of antibodies that is able to capture an antigen molecule; the antibody kinetics refers to the rate at which the active antibodies are able to capture antigen molecules. Second, we study how the antibody functionalized particles behave in a biosensor where the nanoparticles are used as a label, i.e., where the particles capture antigen molecules and also function as labels for immuno-sandwich detection. As a model system we have used superparamagnetic particles with a diameter of 500 $\mathrm{nm}$, onto which monoclonal anti-troponin antibodies were covalently bound. The advantage of using magnetic particles is that they can be conveniently manipulated by magnetic fields and detected in an optomagnetic biosensor platform. ${ }^{3}$ Cardiac troponin is a gold standard for the diagnosis of acute myocardial infarction ${ }^{15}$ and is therefore highly relevant for point-of-care diagnostic applications.

\section{EXPERIMENTAL SECTION}

Materials. Superparamagnetic MasterBeads with carboxylic acid coating (average diameter $500 \mathrm{~nm}$ ) and storage buffer were purchased from Ademtech (France). The amount of nanoparticles in the stock solution was provided by the supplier, namely $3.1 \times 10^{11}$ particles in a $1 \mathrm{~mL}$ stock solution with $5.0 \mathrm{wt}$ $\%$ particle concentration. Cardiac troponin I (cTnI, in the form of troponin ITC complex, molecular weight $26 \mathrm{kDa}$ ) and monoclonal anti-troponin I antibody (mouse IgG, molecular weight $150 \mathrm{kDa}$ ) were purchased from Hytest (Finland). The cTnI samples for assay experiments were prepared by spiking cTnI in assay buffer ( $5 \%$ bovine serum albumin (BSA) in phosphate buffered saline (PBS)) or in a human plasma pool.

Functionalization of Magnetic Nanoparticles with Antibodies. Magnetic nanoparticles (MNP) were funtionalized with anti-troponin antibodies at different surface coverages.
The immobilization conditions, e.g., $\mathrm{pH}$ and EDC to antibody ratio, were the result of an optimization process for high antibody activity. Briefly, the MNPs were washed twice with 15 mM MES buffer (2-( $N$-morpholino)ethanesulfonic acid, $\mathrm{pH}$ 6.0) by holding the particles with a magnet and resuspended in MES buffer. The nanoparticle surface was then activated by incubation with EDC (N-3-(dimethylamino)propyl- $N$-ethylcarbodimide hydrochloride) and sulfo-NHS (N-hydroxysulfosuccinimide) at an end concentration of $2 \mathrm{mg} \mathrm{mL}^{-1}(12.8 \mu \mathrm{M})$ and $0.5 \mathrm{mg} \mathrm{mL}^{-1}(2.3 \mu \mathrm{M})$ in an incubator shaker (1000 rpm) at room temperature. After incubation with EDC and sulfoNHS for $30 \mathrm{~min}$, the particles were separated by a magnet and washed twice with MES buffer. The antibody solution was then quickly added to the activated particles. The monoclonal antitroponin antibodies (MAb1) were added to a final antibody-toparticle mass ratio ranging from 5 to $100 \mu \mathrm{g}$ of antibody per 1 mg of nanoparticles. Antibodies and particles were incubated under continuous stirring $(1000 \mathrm{rpm})$ at room temperature for $30 \mathrm{~min}$. After incubation, the supernatant was removed by holding the particles with a magnet and the particles were further incubated with Tris- $\mathrm{HCl}$ solution $(50 \mathrm{mM}, \mathrm{pH} 7.4)$ for $30 \mathrm{~min}$ to deactivate the unbound carboxyl groups on the particle surface. This was followed by two washing steps with storage buffer (Ademtech, France). Finally, the antibody coupled nanoparticles were resuspended in storage buffer at an end concentration of $10 \mathrm{mg} \mathrm{mL}^{-1}$ and stored at $4{ }^{\circ} \mathrm{C}$ after sonication. Samples were also sonicated briefly after each magnetic separation step performed in the antibody coupling protocol. The loss of particles in pipetting and magnetic separation steps was negligible.

Number of Antibodies Per Nanoparticle. The amount of immobilized antibody was quantified by a supernatant assay of the anti-troponin antibody using a commercial Easy-Titer Antibody Assay Kit (Thermo Scientific, Pdt. No. 23300, see the Supporting Information). The supernatant antibody concentration was measured in $\mathrm{ng} \mathrm{mL} \mathrm{mL}^{-1}$, from which the amount of immobilized antibody (in $\mu \mathrm{g} \mathrm{mg}^{-1}$ of nanoparticles) could be determined. The number of immobilized antibodies per nanoparticle was calculated by dividing the amount of immobilized antibody by the known amount of nanoparticles in the solution, using the antibody molecular weight and nanoparticle concentration data from the supplier (see the Materials section). The experiments were performed in triplicate and the standard deviation was calculated in each case. 
Hydrodynamic Diameter and $\zeta$-Potential. Antibodyfunctionalized magnetic nanoparticles were characterized by measuring the hydrodynamic mean diameter and $\zeta$-potential in a dynamic light scattering (DLS) instrument (Malvern Zetasizer). For dynamic light scattering measurements, the nanoparticles were diluted to 0.05 wt $\%$ in $10 \mathrm{mM} \mathrm{NaCl}$ solution and were sonicated at $50 \mathrm{~W}$ for $3 \mathrm{~s}$ three times before the measurement. For $\zeta$-potential measurement, the nanoparticles were diluted to 0.05 wt $\%$ in $10 \mathrm{mM}$ phosphate buffer $(\mathrm{pH}$ 7.4) and were sonicated as mentioned before. The measurements were performed in triplicate and the standard deviation was calculated in each case.

Quantification of Active Antibodies. The term "active antibodies" refers to the immobilized antibodies on the nanoparticle surface that are able to capture cTnI molecules from solution. To quantify the active antibodies, we exposed the antibody functionalized nanoparticles to cTnI at different concentrations (from 100 to $2500 \mathrm{pM}$ ) and incubated for $1 \mathrm{~h}$ in order to reach equilibrium (verified by kinetic studies). The supernatant cTnI concentration was measured in an optomagnetic f-TIR biosensor platform developed by Philips ${ }^{3,16}$ (see the Supporting Information for the detailed methodology) and the captured cTnI concentration was determined thereafter. After the concentration of captured cTnI was determined, the number of captured cTnI molecules per nanoparticle was calculated by dividing the captured cTnI concentration by the known concentration of nanoparticles in solution (using the cTnI molecular weight and nanoparticle concentration data, see the Materials section). Graphs of cTnI capture as a function of cTnI concentration were plotted for nanoparticles prepared with different antibody densities. The number of active antibodies per nanoparticle was calculated from the saturation levels of cTnI capture (see the Supporting Information, Figure S3).

Kinetics of Troponin Capturing. We have studied the troponin I (cTnI) capturing kinetics of magnetic nanoparticles. Antibody coated nanoparticles (having different antibody surface densities) at a concentration of $0.5 \mathrm{mg} \mathrm{mL}^{-1}$ were incubated with cTnI solutions of different concentrations (100-1000 pM in PBS buffer, $\mathrm{pH} 7.4$ ) in a volume of $500 \mu \mathrm{L}$. At regular time intervals, a small sample volume of $20 \mu \mathrm{L}$ was withdrawn. The nanoparticles in the withdrawn sample were held down with a magnet and the supernatant was analyzed for the cTnI concentration in the above-mentioned f-TIR assay. Dilution steps were applied in order to optimally map the higher cTnI concentration samples into the dose-response curve of the f-TIR assay, as described in the previous paragraph. After measuring the captured cTnI concentrations from the kinetic samples, the number of captured cTnI molecules per nanoparticle was calculated by dividing with the known concentration of functionalized particles. Furthermore, we fitted a first-order kinetic model to the data and analyzed the kinetic rate constants for cTnI capturing at different antibody surface densities. From the kinetic model analysis, the rate constant values of cTnI capturing kinetics were calculated.

Immunoassay Measurement. After investigating the solution-based target capture activity at different antibody surface densities, we also explored its relation with the surfacebinding activity in a sandwich immunoassay in the optomagnetic (f-TIR) biosensor platform. The immunoassay method and optical detection of surface bound nanoparticles was performed as described earlier by Bruls et al. ${ }^{3}$ In short, antibody functionalized nanoparticles were dried inside a microchamber in the disposable f-TIR cartridge. Thereafter, undiluted plasma sample, containing different concentrations of cTnI from $0 \mathrm{pM}$ to $8.3 \times 10^{2} \mathrm{pM}$ (corresponding to $0-20 \mu \mathrm{g}$ $\mathrm{L}^{-1}$ ), was injected into the microchamber that contained the dried-in nanoparticles, in order to record the dose-response curves. The sandwich immunoassay was performed with a first monoclonal antibody (MAb1) on the particles and a second monoclonal antibody (MAb2) on the sensor surface. The concentration of the surface-bound antibodies (MAb2) was kept constant throughout the study. All the assays were performed in triplicate, unless stated otherwise.

\section{RESULTS AND DISCUSSION}

Antibody Surface Coverage on Magnetic Nanoparticles. The amount of antibodies immobilized on nanoparticles via EDC-sNHS chemistry was quantified by a supernatant assay and is plotted against the number of antibodies added per nanoparticle, see Figure 1. From the

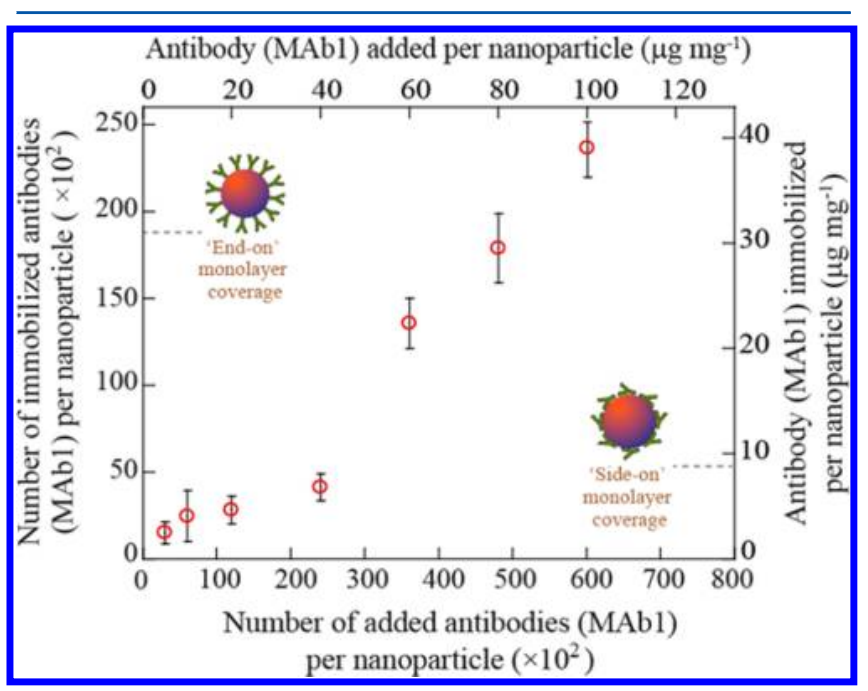

Figure 1. Surface coverage of monoclonal anti-troponin antibodies (MAb1) on $500 \mathrm{~nm}$ superparamagnetic nanoparticles (MNP) as a function of the added antibody concentration in solution, both expressed as number ratios. The supplementary axes show the experimental values expressed as weight ratios (in $\mu \mathrm{g} \mathrm{mg}^{-1}$ ). The immobilized antibody surface coverage increases from a submonolayer to a close-packed side-on monolayer coverage. At the higher regime, the immobilized surface coverage overestimates the theoretical monolayer coverage, calculated based on $500 \mathrm{~nm}$ sphere, which may occur due to a steric adjustment of the antibody conformation and/or the partial formation of a second layer of antibodies on the nanoparticles. Error bars represent the standard deviation calculated from triplicate experiments, which includes the experimental error. The dashed lines represent the calculated MAb1 monolayer coverage considering two molecular orientations (side-on and end-on) on a sphere of $500 \mathrm{~nm}$ diameter.

graph, we see that the antibody immobilization efficiency (the ratio between antibodies bound and antibodies supplied) is in the range of tens of percents. The number of immobilized antibodies increases with the added antibodies in solution, over a wide surface coverage range from $15 \times 10^{2}$ to $236 \times 10^{2}$ monoclonal anti-troponin antibodies (MAb1) per magnetic nanoparticle (MNP). We can relate these numbers to the theoretical surface densities corresponding to two different antibody orientations, namely for side-on and end-on orientations. Given the molecular dimension of the antibody 
molecule $\left(14.5 \times 8.5 \times 4 \mathrm{~nm}^{3}\right)^{17}$ and assuming that the average particle shape is a $500 \mathrm{~nm}$ sphere, we calculate a maximum antibody surface density of $51 \times 10^{2}$ antibodies per nanoparticle for a monolayer of side-on oriented antibodies, and $173 \times 10^{2}$ antibodies per nanoparticle for end-on oriented antibodies; ${ }^{18}$ these numbers are plotted as dashed lines in Figure 1. A surface roughness of the particles will lead to a slightly higher effective surface area per nanoparticle, which would shift these numbers to slightly higher values. The data reveals that the immobilized antibody density increases from a submonolayer to a close-packed side-on monolayer coverage, and at higher antibody concentrations the immobilization density crosses the theoretical monolayer coverage value for $500 \mathrm{~nm}$ spheres. At the highest surface densities, a steric adjustment of the antibody conformation and/or the partial formation of a second layer of antibodies may occur on the nanoparticles. The surface crowding dependent steric adjustment of antibody molecules has been reported before at planar solid-liquid interfaces. ${ }^{19-21}$ The dynamic light scattering data reveals a progressive increase in the hydrodynamic radius of the antibody coated magnetic nanoparticles with the increase in surface coverage. The average hydrodynamic radius of bare carboxylic magnetic nanoparticles was $500 \mathrm{~nm}$, increasing to $560 \mathrm{~nm}$ at higher antibody coverages (see the Supporting Information, Figure S4). The $\zeta$-potential shows a progressive decrease in negative surface potential with the increase of immobilized antibody coverage. At higher coverages of immobilized antibodies, the negative surface potential is found to still decrease while the hydrodynamic radius stabilizes. This may indicate that the antibodies are accommodated onto the nanoparticle surface at the expense of their conformations so that a larger number of antibodies can be immobilized. At very high antibody concentrations, the number of immobilized antibodies saturates at levels in the range between $400 \times 10^{2}$ and $500 \times 10^{2} \mathrm{MAb1} / \mathrm{MNP}$ (data not shown). At such high antibody densities, the fraction of active antibodies becomes extremely low; therefore, we have focused the experiments on surface coverages up to $236 \times 10^{2} \mathrm{MAb1} / \mathrm{MNP}$ (see the Active Antibodies on the Nanoparticles section).

Active Antibodies on the Nanoparticles. We have quantified the number of active antibodies on magnetic nanoparticles by a cTnI supernatant assay, see Figure 2 . We observe that the number of antibodies that can capture cTnI increases from 53 to 130 per nanoparticle and levels off when the antibody surface coverage approaches the side-on monolayer value. Comparing the active antibodies to the total number of immobilized antibodies (right axis), we see that only a small fraction of the immobilized antibodies is able to capture cTnI from solution, across the whole surface coverage range. Only up to $4 \%$ of the immobilized antibodies are active at low surface coverage $\left(15 \times 10^{2} \mathrm{MAb} 1 / \mathrm{MNP}\right)$, decreasing to $0.6 \%$ at higher surface coverages $\left(236 \times 10^{2} \mathrm{MAb} 1 / \mathrm{MNP}\right)$. We attribute these low values of active antibodies at equilibrium to the orientation, denaturation, and/or steric availability of the antibodies. The EDC-sNHS chemistry couples the antibodies at a random orientation, ${ }^{22,23}$ including immobilization via the $\mathrm{NH}_{2}$ groups close to the $\mathrm{F}_{\mathrm{ab}}$ fragment, ${ }^{11,13}$ which can decrease the ability to capture cTnI from solution. Second, the antibody activity may be lowered by unfolding and spreading of antibodies on the nanoparticle surface. At low antibody coverage, more interaction with the surface occurs due to large available surface area, which can lead to spreading/ unfolding of immobilized proteins. ${ }^{24-27}$ And third, the

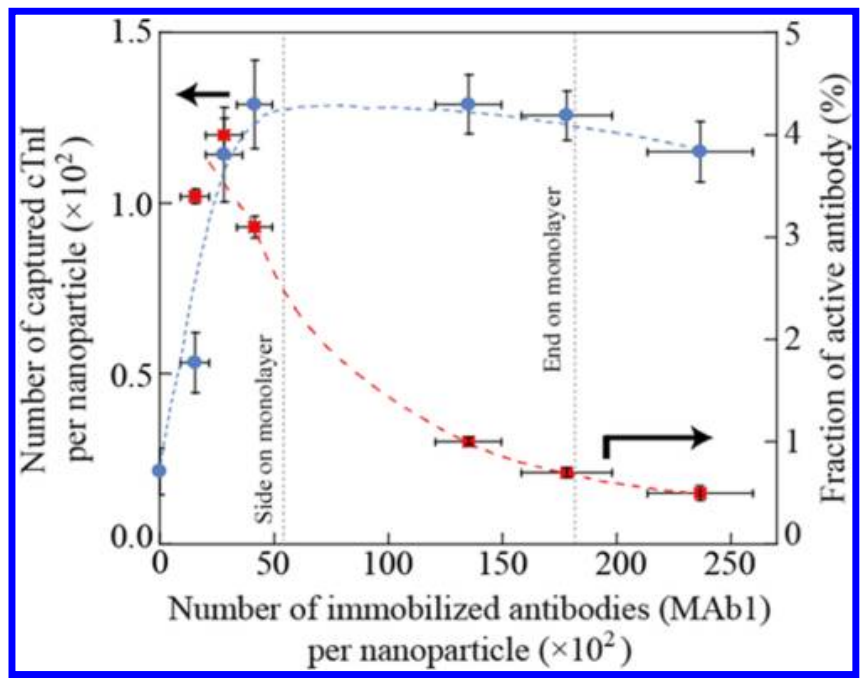

Figure 2. Quantification of active antibodies (which can capture cTnI molecules) at different antibody surface coverage on the nanoparticles. Left axis: Amount of captured cTnI per nanoparticle (blue dashed line) as a function of antibody surface coverage, calculated from the remaining $\mathrm{cTnI}$ in solution. This captured $\mathrm{cTnI}$ amount gives the number of active antibodies per nanoparticle. Right axis: Fraction of antibodies that is active for cTnI capture (red dashed line). The vertical dotted lines represent the theoretical antibody densities for complete side-on and end-on monolayers on a $500 \mathrm{~nm}$ sphere. The dashed lines are guides to the eye.

crowding of antibodies on the nanoparticle surface may affect the antibody conformation and accessibility for cTnI capturing. The DLS and $\zeta$-potential data are in agreement with an interpretation that at high surface densities, the antibodies get immobilized on the nanoparticle surface in expense of their three-dimensional conformation. So at the higher surface densities, it is likely that a crowding of antibodies effect has a negative effect on the cTnI capturing activity of the antibodies.

Several studies have investigated the crowding effect of immobilized antibodies on their ability to capture targets on planar surfaces. ${ }^{19-21} \mathrm{Xu}$ et al. reported a sharp decrease in antigen binding molar ratio to $5 \%$ beyond half-monolayer surface coverage of immobilized antibodies on planar silica substrates. ${ }^{19}$ Zhao et al. reported similar decreases (down to $3 \%$ ) in the antigen binding molar ratio when the surface density of immobilized antibodies increased beyond a monolayer coverage on planar silica substrates. ${ }^{20}$ They pointed to the increasing steric hindrance with the increase in packing density as one of the major factors that interferes with the target capture from solution. In these studies, the molar ratios at low antibody densities were reported to be several tens of percents, but unfortunately, numbers were not given for the level of nonspecific binding in absence of antibodies. In the limit of low antibody density, the nonspecific binding of target to the bare surface dominates the capturing process. Therefore, in a control experiment, we have analyzed the nonspecific binding of cTnI molecules to magnetic nanoparticles without antibodies. For this purpose, magnetic nanoparticles underwent the complete surface activation and deactivation process, however without antibodies being present in the solution. These nanoparticles were incubated with excess cTnI molecules and we found that around $20 \mathrm{cTnI}$ molecules per nanoparticle were bound nonspecifically at equilibrium (Figure 2). The binding of cTnI molecules to the $\mathrm{COOH}$ magnetic nanoparticles may originate from different nonspecific interactions, namely, 
hydrophobic interaction, van der Waals interaction, and/or hydrogen bonding. ${ }^{28}$ The cTnI capture amount for the lowest antibody density $\left(15 \times 10^{2} \mathrm{MAb} 1 / \mathrm{MNP}\right)$ is 2 times higher than the amount in the control experiment. This indicates that data taken at even lower antibody densities, i.e., $\leq 15 \times 10^{2}$ MAb1/MNP, will be dominated by nonspecific interactions.

Kinetics of cTnl Capture. The kinetic data of cTnI capturing was analyzed with the Langmuir kinetic model where the fractional coverage of immobilized antibodies by cTnI, $\theta(t)$ at time $t$, is expressed as ${ }^{29,30}$

$$
\frac{\mathrm{d} \theta}{\mathrm{d} t}=K_{\mathrm{on}} \cdot C_{\mathrm{T}}(t) \cdot(1-\theta)-K_{\mathrm{off}} \cdot \theta
$$

Here $C_{\mathrm{T}}(t)$ is the $\mathrm{cTnI}$ concentration in solution at time $t$, and $k_{\text {on }}\left(\mathrm{M}^{-1} \mathrm{~s}^{-1}\right)$ and $k_{\text {off }}\left(\mathrm{sec}^{-1}\right)$ are the kinetic parameters. Now, evaluating the concentration of $\mathrm{cTnI}$ captured antibodies, $C_{\mathrm{A}-\mathrm{T}}$ $(t)$ at time $t$, from eq 1 , we get (see the Supporting Information):

$$
\begin{aligned}
\frac{\mathrm{d}}{\mathrm{d} t}\left\{C_{\mathrm{A}-\mathrm{T}}(t)\right\}= & k_{\text {on }}\left\{C_{\mathrm{A}}(0) \cdot C_{T}(0)-\left(C_{\mathrm{A}}(0)+C_{\mathrm{T}}(0)\right.\right. \\
& \left.\left.+\frac{k_{\text {off }}}{k_{\text {on }}}\right) C_{\mathrm{A}-\mathrm{T}}(t)+C_{\mathrm{A}-\mathrm{T}}^{2}(t)\right\}
\end{aligned}
$$

where $C_{\mathrm{T}}(0)$ is the initial cTnI concentration and $C_{\mathrm{A}}(0)$ is the volume concentration of active antibodies, which can be calculated from the number of active antibodies per nanoparticle multiplied by the nanoparticle concentration in the solution. The kinetic data with different cTnI concentrations and with different antibody concentrations was fitted with eq 2 using MATLAB software, in order to extract the kinetic parameters. The active antibody concentration, $C_{A}(0)$, and the initial cTnI concentration, $C_{\mathrm{T}}(0)$, have been used as input parameters for the respective curve fitting.

cTnl Capture Kinetics at Different cTnl Concentrations. Kinetic data of cTnI capture at different cTnI concentrations has been recorded for nanoparticles with a near-monolayer antibody surface $\left(41 \times 10^{2} \mathrm{MAbl} / \mathrm{MNP}\right.$, see the Supporting Information, Figure S5a). The data show that the capture reaches equilibrium within 30 min irrespective of the initial cTnI concentration, indicating that the antibody concentration dominantly determines the capture time constant. The equilibrium amount of cTnI capture scales linearly with the cTnI concentration at low values (from 100 to $500 \mathrm{pM}$ ), but scales sublinearly at high values (from 500 to $1000 \mathrm{pM}$ cTnI). This indicates that antibody saturation by cTnI is approached at the high cTnI concentration levels. The fits with eq 2 are represented by the solid lines in Figure S5a (Supporting Information). The fits give values for the association rate constant $\left(k_{\text {on }}\right)$ of the antibody-coated nanoparticles for each $\mathrm{cTnI}$ concentration. The fitted $k_{\text {on }}$ values at these cTnI concentrations are in the range of $10^{6} \mathrm{M}^{-1} \mathrm{~s}^{-1}$ (see the Supporting Information, Figure S5), which is in agreement with literature values for typical antibody antigen reactions. ${ }^{31-33}$ We could also obtain the equilibrium dissociation constant, $K_{\mathrm{d}}$, which is in the range of $10^{-11} \mathrm{M}$ in the cTnI concentration range used.

cTnl Capture Kinetics at Different Antibody Coverages. We have studied the cTnI capture kinetics with surface coverages of $15 \times 10^{2}$ to $236 \times 10^{2} \mathrm{MAb1} / \mathrm{MNP}$, for $500 \mathrm{pM}$ cTnI and a particle concentration of $0.5 \mathrm{mg} \mathrm{mL}^{-1}$, see Figure 3a. From the graph, we see that the nanoparticles having less

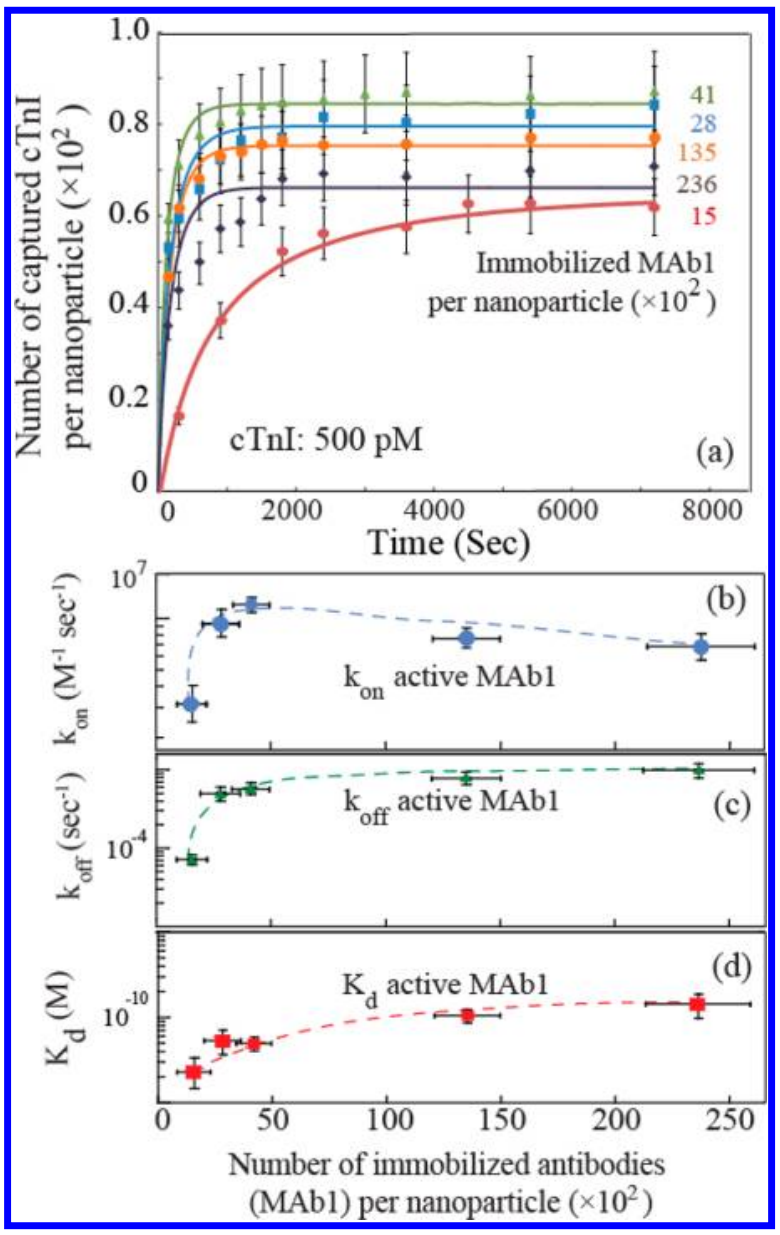

Figure 3. Kinetic analyses of solution-based cTnI capture in buffer (PBS buffer, $\mathrm{pH}$ 7.4): (a) by antibody-coated nanoparticles at different surface coverages (from $15 \times 10^{2}$ to $236 \times 10^{2} \mathrm{MAbl} / \mathrm{MNP}$ ). This set of experiments has been performed with $500 \mathrm{pM}$ of cTnI in solution. The kinetic model expressed in eq 2 has been fitted to the data, and fits are represented by the solid lines. Kinetic parameters of active antibodies were further determined from this fit: (b) association rate constants $\left(k_{\text {on }}\right),(\mathrm{c})$ dissociation rate constants $\left(k_{\text {off }}\right)$, and (d) equilibrium dissociation constant $\left(K_{\mathrm{d}}\right)$ values of cTnI capture at different antibody surface coverages. Error bars represent the standard deviation calculated from triplicate experiments, which includes the experimental error. Dashed lines are guides to the eye.

immobilized antibodies on their surface take a longer time to reach the steady state compared with the higher antibody loaded particles. Nanoparticles having $15 \times 10^{2}$ antibodies on their surface reached steady state in about 50 min whereas the particles having $236 \times 10^{2}$ antibodies took about $20 \mathrm{~min}$ to reach steady state. Moreover, the steady-state captured amount of cTnI initially scales up with the immobilized MAb1/MNP and goes down at higher antibody coverages. This behavior is in agreement with the data of Figure 2. We have fitted the kinetic model of eq 2 to the data of Figure 3. The kinetic parameters of the active antibodies were calculated from these fits and are plotted against the antibody surface coverage (Figure $3 b, c, d$ ). The data show that the association $\left(k_{\mathrm{on}}\right.$, Figure $\left.3 \mathrm{~b}\right)$ and dissociation ( $k_{\text {off }}$ Figure $3 \mathrm{c}$ ) rate constants of the active antibodies are or the order of $10^{6}$ and $10^{-4} \mathrm{~s}^{-1}$, respectively. Nanoparticles with the lowest antibody coverage $\left(15 \times 10^{2}\right.$ $\mathrm{MAb1} / \mathrm{MNP}$ ) showed lower $k_{\text {on }}$ and $k_{\text {off }}$ values compared to higher antibody coverages. We attribute this result to partial 
spreading/unfolding of the antibodies at the lowest surface coverage, which can lead to the altered affinity of the immobilized antibodies toward cTnI. At the highest surface coverages, the $\mathrm{k}_{\text {on }}$ of the active antibodies is affected due to surface crowding. We have calculated the equilibrium dissociation constant $\left(K_{\mathrm{d}}\right)$ of active antibodies from the kinetic model fitting (see Figure 3d), which gives values in the range between $5 \times 10^{-11}$ and $1 \times 10^{-10} \mathrm{M}^{-1} \mathrm{~s}^{-1}$ for the different antibody surface coverages.

We have further evaluated the equilibrium dissociation constant $\left(K_{\mathrm{d}}\right)$ values at different MAb1 coverage with the well-known Langmuir isotherm model: ${ }^{34-36}$

$$
C_{\mathrm{A}-\mathrm{T}}(\mathrm{e})=\frac{C_{\mathrm{A}-\mathrm{T}}(\max ) \cdot C_{\mathrm{T}}(\mathrm{e})}{K_{\mathrm{d}}+C_{\mathrm{T}}(\mathrm{e})}
$$

where $C_{A-T}(e)$ and $C_{T}(e)$ are, respectively, the captured and remaining cTnI concentration at equilibrium, $K_{d}$ is the Langmuir dissociation constant, and $\mathrm{C}_{\mathrm{A}-\mathrm{T}}(\max )$ is the maximum amount of cTnI that can be captured by the antibody-coated nanoparticles at increasing cTnI concentrations. We have fitted the equilibrium cTnI captured data as a function of remaining cTnI in solution using eq 3 (see the Supporting Information, Figure S6). The dissociation constant values obtained from the equilibrium analysis (eq 3 fitted in Figure S6 (Supporting Information)) and obtained from the kinetic analysis (eq 2 fitted in Figure 3a) are both plotted in Figure S7 (Supporting Information). The derived dissociation constants are comparable within about a factor of 2 .

Distribution of Dissociation Constants. The data in Figure 2 shows that only a small fraction (a few percent) of immobilized antibodies is able to capture cTnI molecules from solution, and the data in Figures 3 and 4 show that the active antibodies have good binding properties. The data in Figure 3 (kinetics) and Figure S6 (Supporting Information) (equilibrium) have been fitted using a model with a single active antibody population. This raises the question whether we can also extract quantitative information about the binding properties of the large inactive antibody fraction. We assume that the immobilized antibodies have a distribution of binding affinities for the target antigen in solution. The antibodies having the strongest binding affinity ( $4 \%$ of the total immobilized antibody) possess a $K_{d}$ value in the range of $10^{-10} \mathrm{M}$. In the Supporting Information, we have expressed the binding equations for a heterogeneous population of immobilized antibodies on the nanoparticles, for a simplified dual-fraction distribution: a small fraction with a low dissociation constant $K_{\mathrm{d} 1}$, and a large fraction with a higher dissociation constant $\left(K_{\mathrm{d} 2}\right)$. Knowing that $K_{\mathrm{d} 1} \sim 10^{-10} \mathrm{M}$, we can estimate that the dissociation constant range of the weakly binding antibodies should be much larger than $3 \times 10^{-9} \mathrm{M}$.

Immunoassay performance. The immunoassay experiments were performed using nanoparticles having a surface coverage of $15 \times 10^{2}$ to $236 \times 10^{2}$ antibodies. Dose-response curves were recorded on a nanoparticle based opto-magnetic biosensor platform, with cTnI in undiluted blood plasma, see Figure $4 \mathrm{a}$. The slope of the dose-response curves increases with the increase of antibody surface coverage on the nanoparticles, as a higher optical signal (\%) is measured with higher surface antibody coverage, at a given cTnI concentration (Figure 4a). The maximum slope is measured at an antibody surface coverage of about $200 \times 10^{2} \mathrm{MAb1} / \mathrm{MNP}$, which is significantly higher than the antibody surface coverage value
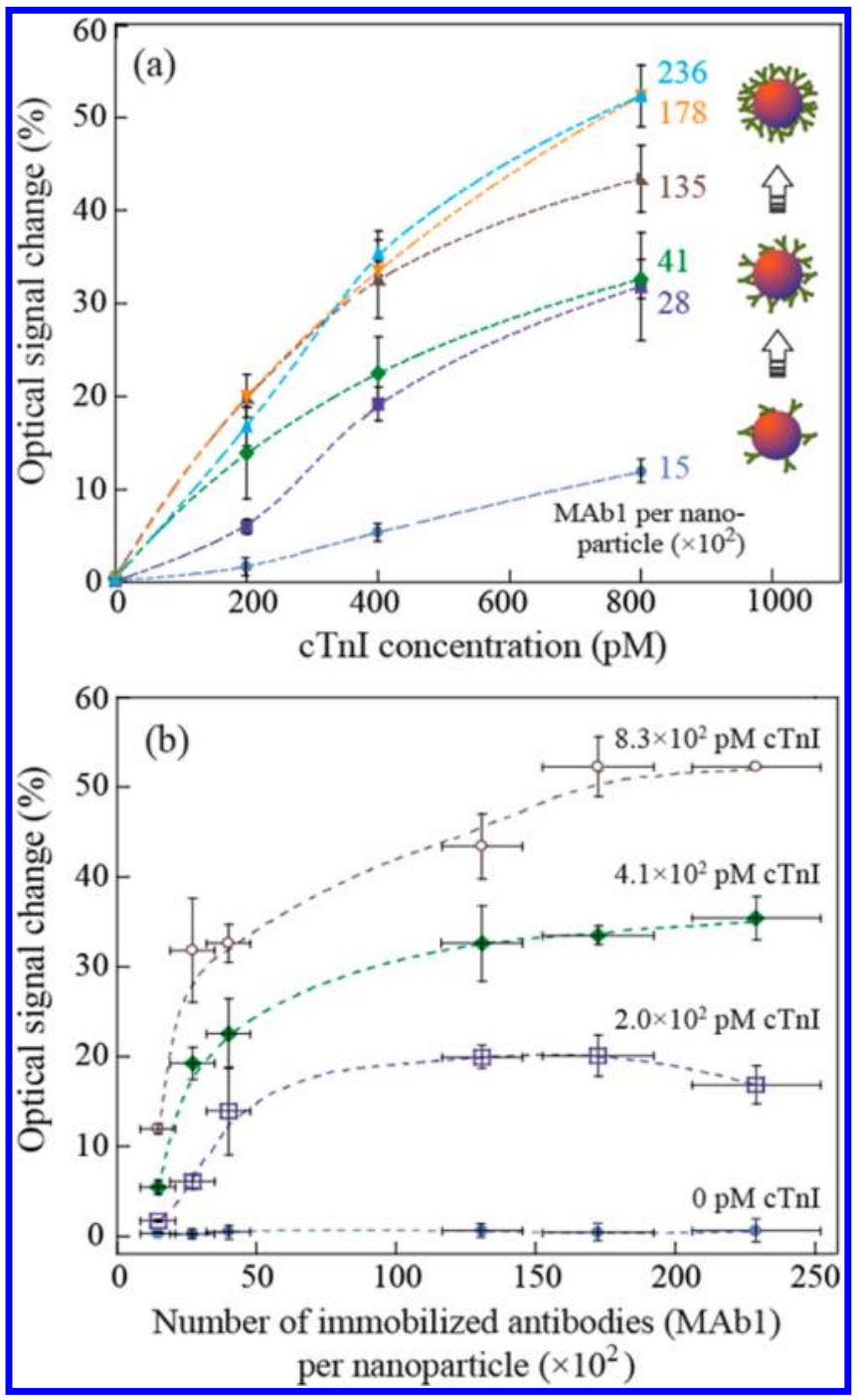

Figure 4. Immunoassay response of the antibody functionalized nanoparticles (with different amounts of immobilized antibodies) in the optomagnetic immunoassay biosensor (see also Figure S1 (Supporting Information)). The assays were performed with undiluted blood plasma spiked with cTnI at concentrations ranging from 0 to 8.3 $\times 10^{2}$ pM. (a) Dose response curve for magnetic nanoparticles with different antibody coverages. (b) Data of panel a plotted as a function of immobilized antibody coverage on the nanoparticles. Error bars represent the standard deviation calculated from triplicate experiments, which includes the experimental error. Dashed lines are guides to the eye.

where the maximum antigen capturing was measured in the supernatant assay $\left(50 \times 10^{2} \mathrm{MAb1} / \mathrm{MNP}\right.$, see Figure 2$)$. The lower optical signal (\%) at low antibody surface coverage can be attributed to the fact that a lower density of antibodies is present on the nanoparticles, resulting in slower assay kinetics. The total assay time in the f-TIR biosensor experiment is less than $10 \mathrm{~min},{ }^{3}$ which is less than the time to equilibrium in the case of the lowest antibody coverage $\left(15 \times 10^{2} \mathrm{MAb1} / \mathrm{MNP}\right)$.

Figure $4 \mathrm{~b}$ shows the optical signal change (\%) as a function of the antibody surface coverage on the nanoparticles. The optical signal initially scales up with the antibody coverage $\left(\leq 41 \times 10^{2} \mathrm{MAb1} / \mathrm{MNP}\right)$ and approaches a plateau at higher antibody coverage $\left(\geq \sim 100 \times 10^{2} \mathrm{MAb} 1 / \mathrm{MNP}\right)$; this trend is similar to the amount of active antibodies at increasing antibody coverage (see Figure 2), showing that the immuno- 


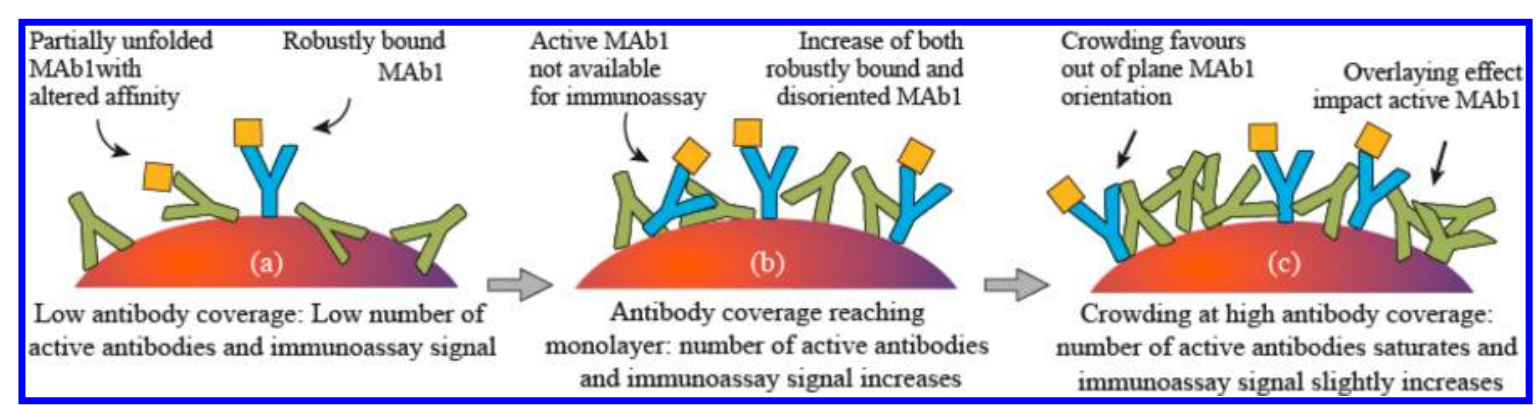

Figure 5. Molecular picture of immobilized antibodies at different surface coverages. (a) First case: at very low antibody coverage, the majority of the activity is contributed by robustly immobilized antibody molecules (blue). Due to the availability of free surface area, antibodies can have multiple interactions with the nanoparticle surface, which can cause disorientation and denaturing (green), thereby affecting the affinity toward the antigen. (b) Second case: when incubation occurs with a higher solution concentration of antibodies, the surface coverage approaches a full monolayer, and less surface is available for side-on antibody orientation and antibody denaturing. As a result, the total number of active antibodies increases. Of the active antibodies, not all are able to bind to a sensor surface in a sandwich immunoassay. (c) Third case: with an even higher antibody solution concentration during incubation, the immobilization capacity crosses the calculated monolayer coverage, and the overall number of active antibodies stabilizes. Possibly two mechanisms play a role: the increasing antibody density may on the one hand favor an out-of-plane antibody orientation due to antibody-antibody steric effects, but may on the other hand, cause inaccessibility of antibodies by overlaying effects. The out-of-plane antibody orientation is favorable for sandwich binding of the nanoparticles to a sensing surface. The molecular picture depicts discrete cases where nanoparticles were incubated with different antibody solution concentrations, not a continuous process of increasing amount of antibody.

assay response is at least partially limited by the antibody surface coverage on the nanoparticles. Interestingly, beyond $\sim 100 \times 10^{2} \mathrm{MAb1} / \mathrm{MNP}$, there is still a slight increase in the optical signal, where the cTnI capturing activity has clearly saturated (see Figure 2). We attribute this observation to a still increasing outward orientation of the antibodies at high antibody coverages, thereby improving the accessibility for binding to a biosensor surface.

Molecular Picture. From the above analysis, we can conceive a molecular picture of the antigen capturing activity and immunoassay performance of immobilized antibodies at different surface coverages on the nanoparticle surface, see Figure 5. From the data, we conclude that the immobilized antibodies constitute several subpopulations. One set of antibody molecules is robustly immobilized with a high affinity for antigen capturing and for binding to a biosensor surface in a sandwich immunoassay (blue, outward oriented). Another set of antibodies (green) is immobilized with a strong loss of antigen-binding activity, e.g., due to immobilization via its antigen binding site or due to conformational unfolding. A third set of antibodies (blue, side oriented) is efficiently able to capture antigen molecules from solution, but is not able to contribute to surface binding in a biosensor immunoassay. At low surface coverages (Figure 5a), the majority of the capturing activity is contributed by a small fraction of immobilized antibodies which are robustly bound, and many antibody molecules are inactive, probably due to partial unfolding/ denaturation by having multiple interactions with the open particle surface. As the number of immobilized antibodies is low in this regime, the total activity is low. Due to the low surface coverage, antibodies with altered affinity can still be exposed to antigen molecules and can capture them from solution, which may be at the origin of the lower $k_{\text {on }}$ and $k_{\text {off }}$ values in this regime. When the nanoparticles are incubated with a higher concentration of antibodies, more antibodies are immobilized onto the surface area, which leads to an antibody density close to monolayer coverage (Figure $5 b$ ). This results in an increase of the total amount of active antibodies, and correspondingly, to a higher immunoassay signal. During the incubation with a high antibody concentration in solution, the nanoparticle surface is rapidly coated with antibodies. Therefore, we assume that the chance to have multiple covalent bonds between an antibody and the nanoparticle surface is lowered due to the time constraint. This may lead to less unfolding/denaturation and more out-of-plane oriented antibodies, and thereby to an increase of antibody affinity. When the antibody solution concentration is even higher, the immobilization capacity crosses the calculated monolayer coverage (Figure 5c). However, the overall number of active antibodies does not increase, as found in the experimental data (Figure 2). In this regime, two mechanisms may occur simultaneously. Due to crowding, the antibodies may favorably orient in an out-ofplane direction, which can increase the number of active antibodies. On the other hand, antibodies may become shielded by other antibodies, thereby decreasing the antibody accessibility. The saturation of capturing activity observed in Figure 2 suggests that positive and negative mechanisms are balanced. Yet, the slight increase of immunoassay signal observed in Figure $4 \mathrm{~b}$ at high antibody surface coverage, suggests that the crowding effect may favor antibody orientations in such a way that more active antibodies are available for binding to the sensor surface in the sandwich immunoassay. This is sketched in Figure $5 \mathrm{c}$ as an increased outward orientation of the active antibodies (blue, outward oriented).

\section{CONCLUSIONS}

We have quantified the solution based antigen capturing activity of antibodies immobilized on magnetic nanoparticles, for a wide range of surface coverages, with cTnI as the model antigen. The number of active antibodies that can capture antigen molecules from solution increases with surface coverage initially and saturates in the monolayer coverage regime. We find that only a small fraction (about 4\%) of the total immobilized antibodies is able to capture antigen from solution, which decreases even more as the antibody coverage increases. We attribute this result to the random orientation and possible unfolding of the immobilized antibodies at low surface coverage, and to additional crowding effects at higher coverages. These mechanisms can impair the availability of $\mathrm{Fab}$ fragments to capture antigen molecules. Interestingly, the kinetic analysis of cTnI capture reveals $K_{d}$ values in the range of 
$10^{-10} \mathrm{M}$ throughout these antibody coverages. The association $\left(k_{\text {on }}\right)$ and dissociation $\left(k_{\text {off }}\right)$ rate constants are lowest for the lowest antibody coverage; low $k_{\text {on }}$ may be caused by the altered affinity of antibodies due to the partial unfolding/spreading on the nanoparticle surface. With increasing antibody coverage, the fraction of active antibodies decreases but the kinetic properties of the active antibodies are stable. Furthermore, in the sandwich immunoassay platform, the surface binding activity of the antibody coated nanoparticles was studied. The biosensor signal is clearly dependent on the antibody surface coverage of the nanoparticles, following the trend observed for the antigen capturing activity in solution. Interestingly, at the higher surface coverage $\left(10^{4} \mathrm{MAb1} / \mathrm{MNP}\right)$, the solution capturing activity saturates, while the biosensor signal still shows a slight increase. This may point to an increase of the outward orientation of active antibodies at high antibody surface densities.

This study has been performed with certain experimental conditions (biomarker cTnI, carboxyl-functionalized polymercoated magnetic nanoparticles, IgG antibody class, covalent immobilization), which are commonly applied in antibody based biosensing assays. The EDC-NHS covalent immobilization gives a very stable link, but our study shows that the fraction of active antibodies can be very low. A low antibody fraction compromises the signal in immunoassays; and vice versa, the high fraction of inactive antibodies results in a large unused surface area that is prone to nonspecific binding. In spite of the small number of active antibodies, our study shows that these active antibodies have low equilibrium dissociation constants. It will be interesting to study if this phenomenon (low active antibody fraction, yet with low dissociation constants) is also expressed by other systems (biomarkers, antibodies, nanoparticles, coupling protocols). The value of the dissociation constant is a key parameter and may be one of the reasons why EDC-NHS coupling methods are successfully used in a vast range of immunobiosensing technologies.

As a next step, the developed supernatant assay methodology can be applied to quantitatively characterize the capturing functionality of other surface biofunctionalizations, comparing, e.g., directional and nondirectional coupling methods, and methods with linkers between antibodies and surface, for different linker types and linker lengths. Importantly, the studies should address the number, activity, and kinetics of the immobilized antibodies. Furthermore, it will be interesting to test the molecular picture sketched in Figure 5, where systematic changes of antibody number and antibody orientation are hypothesized. These parameters may be quantified in capture assays using biomolecules that bind to specific parts of the immobilized antibody molecules, e.g., secondary antibodies, protein $\mathrm{G}$, protein A. Furthermore, the molecular picture may be clarified using techniques with singlemolecule resolution, e.g., by recognition imaging atomic force microscopy ${ }^{37}$ or force induced dissociation experiments. ${ }^{38}$ The present and future studies on the fundamental aspects of antibody activity will play an important role in reaching the maximum levels of sensitivity, specificity, and kinetics in future diagnostic and therapeutic technologies based on antibodyfunctionalized particles.

\section{ASSOCIATED CONTENT}

\section{S Supporting Information}

The $\zeta$-potential and DLS characterization data of antibody coated magnetic nanoparticles and further analysis of equilibrium and kinetics capturing of cTnI. This material is available free of charge via the Internet at http://pubs.acs.org.

\section{AUTHOR INFORMATION}

\section{Corresponding Author}

*M. W. J. Prins. E-mail: m.w.j.prins@tue.nl.

\section{Present Address}

${ }^{\ddagger}$ Eindhoven University of Technology, The Netherlands.

\section{Notes}

The authors declare no competing financial interest.

\section{ACKNOWLEDGMENTS}

The authors thank H. van Zon, R. van Lieshout, M. Irmscher, and many colleagues at Philips Research for valuable support and discussion. The work of B.S. was partly funded by the European Commission through the 7th Framework Programme (FP7-MC-ITN BioMaX, project number 264737).

\section{REFERENCES}

(1) Mahmoudi, M.; Lynch, I.; Ejtehadi, M. R.; Monopoli, M. P.; Bombelli, F. B.; Laurent, S. Chem. Rev. 2011, 111, 5610-5637.

(2) Mieszawska, A. J.; Mulder, W. J. M.; Fayad, Z. A.; Cormode, D. P. Mol. Pharmaceutics 2013, 10, 831-847.

(3) Bruls, D. M.; Evers, T. H.; Kahlman, J. A. H.; van Lankvelt, P. J. W.; Ovsyanko, M.; Pelssers, E. G. M.; Schleipen, J. J. H. B.; de Theije, F. K.; Verschuren, C. A.; van der Wijk, T.; van Zon, J. B. A.; Dittmer, W. U.; Immink, A. H. J.; Nieuwenhuis, J. H.; Prins, M. W. J. Lab Chip 2009, 9, 3504-3510.

(4) Nichkova, M.; Dosev, D.; Gee, S. J.; Hammock, B. D.; Kennedy, I. M. Anal. Chem. 2005, 77, 6864-6873.

(5) Hermanson, G. T. Bioconjugate Techniques; 2nd ed.; Academic Press Inc.: Amsterdam, 2008.

(6) Masri, M. S.; Friedman, M. I. Protein Chem. 1988, 7, 49-54.

(7) Fernandez-Lafuente, R.; Rosell, C. M.; Rodriguez, V.; Santana, C.; Soler, G.; Bastida, A.; Guisan, G. M. Enzyme Microb. Technol. 1993, $15,546-550$.

(8) Mateo, C.; Abian, O.; Fernandez-Lorente, G.; Pedroche, J.; Fernandez-Lafuente, R.; Guisan, J. M. Biotechnol. Prog. 2002, 18, 629634.

(9) Lin, P. C.; Chen, S. H.; Wang, K. Y.; Chen, M. L.; Adak, A. K.; Hwu, J. R. R; Chen, Y. J.; Lin, C. C. Anal. Chem. 2009, 81, 87748782.

(10) Brogan, K. L.; Schoenfisch, M. H. Langmuir 2005, 21, 30543060.

(11) Kausaite-Minkstimiene, A.; Ramanaviciene, A.; Kirlyte, J.; Ramanavicius, A. Anal. Chem. 2010, 82, 6401-6408.

(12) Song, H. Y.; Zhou, X.; Hobley, J.; Su, X. Langmuir 2012, 28, 997-1004.

(13) Vashist, S. K.; Dixit, C. K.; MacCraithad, B. D.; O’Kennedy, R. Analvst 2011, 136, 4431-4436.

(14) Xu, H.; Zhao, X.; Lu, J. R.; Williams, D. E. Biomacromolecules 2007, 8, 2422-2428.

(15) Morrow, D. A.; Cannon, C. P.; Jesse, R. L.; Newby, L. K.; Ravkilde, J.; Storrow, A. B.; Wu, A. H. B.; Christenson, R. H.; Apple, F. S.; Francis, G.; Tang, W. Clin. Chem. (Washington, DC, U. S.) 2007, 53, $552-574$.

(16) Dittmer, W. U.; Evers, T. H.; Hardeman, W. M.; Huijnen, W.; Kamps, R.; de Kievit, P.; Neijzen, J. H.; Nieuwenhuis, J. H.; Sijbers, M. J.; Dekkers, D. W.; Hefti, M. H.; Martens, M. F. Clin. Chim. Acta 2010, $411,868-873$.

(17) Sarma, V. K.; Silverton, E. W.; Davies, D. R.; Terry, W. D. J. Biol. Chem. 1971, 246, 3753-3759.

(18) Buijs, J.; Lichtenbelt, J. W. T.; Norde, W.; Lyklema, J. Colloid Surf. B 1995, 5, 11-23.

(19) Xu, H.; Lu, J. R.; Williams, D. E. J. Phys. Chem. B 2006, 110, $1907-1914$ 
(20) Zhao, X.; Pan, F.; Cowsill, B.; Lu, J. R. Langmuir 2011, 27, $7654-7662$.

(21) Bonanno, L. M.; DeLouise, L. A. Langmuir 2007, 23, 58175823.

(22) Hoare, D. G.; Koshland, D. E., Jr. I. Am. Chem. Soc. 1966, 88, $2057-2058$.

(23) Staros, J. V. Biochemistry 1982, 21, 3950-3955.

(24) Norde, W.; Favier, J. P. Colloids Surf. 1992, 64, 87-93.

(25) Kim, J.; Somorjai, G. A. I. Am. Chem. Soc. 2003, 125, 31503158.

(26) Cheng, Y. Y.; Chang, H. C.; Hoops, G.; Su, M. C. J. Am. Chem. Soc. 2004, 126, 10828-10829.

(27) Buijs, J.; Hlady, V. I. Colloid Interface Sci. 1997, 190, 171-181.

(28) Ta, T. C.; McDermott, M. T. Anal. Chem. 2000, 72, 2627-2634.

(29) Connors, K. A. Chemical Kinetics: The Study of Reaction Rates in Solution; VCH Publishers: New York, 1991.

(30) Atkins, P.; de Paula, J. Physical Chemistry, $9^{\text {th }}$ ed.; W. H. Freeman Publishers: New York, 2009.

(31) Stenberg, M.; Nygren, H. I. Immunol. Methods 1988, 113, 3-15.

(32) Mani, V.; Wasalathanthri, D. P.; Joshi, A. A.; Kumar, C. V.; Rusling, J. F. Anal. Chem. 2012, 84, 10485-10491.

(33) Soukka, T.; Halrmal, H.; Paukkunen, J.; Lolvgren, T. Anal. Chem. 2001, 73, 2254-2260.

(34) Langmuir, I. I. Am. Chem. Soc. 1916, 38, 2221-2295.

(35) Langmuir, I. I. Am. Chem. Soc. 1917, 39, 1848-1906.

(36) Grant, P. G.; Lemke, S. L.; Dwyer, M. R.; Phillips, T. D. Langmuir 1998, 14, 4292-4299.

(37) Ebner, A.; Wildling, L.; Zhu, R.; Rankl, C.; Haselgrübler, T.; Hinterdorfer, P.; Gruber, H. I. Top. Curr. Chem. 2008, 285, 29-76.

(38) Jacob, A.; van IJzendoorn, L. J.; de Jong, A. M.; Prins, M. W. J. Anal. Chem. 2012, 84, 9287-9294. 